Revista de Psicología Vol. 33 (1), 2015 (ISSN 0254-9247)

\title{
Construcción y validación de una escala de actitudes negativas hacia personas trans
}

\author{
José Páez ${ }^{1}$, Guillermo Hevia ${ }^{2}$, Florencia Pesci ${ }^{3}$ y Hugo H. Rabbia ${ }^{4}$ \\ Universidad Nacional de Córdova - Argentina
}

Se construye y valida psicométricamente una escala de actitudes negativas hacia personas trans (EANT) como expresión del prejuicio hacia las mismas. Se reportan dos estudios secuenciales interdependientes por cuestionarios a partir de muestreos no probabilísticos. El estudio 1, con 203 participantes, en su mayoría estudiantes universitarios, aborda la construcción y análisis exploratorio de la EANT. El estudio 2, con 408 participantes según cuotas $s$ ociodemográficas establecidas por el censo nacional en la población general, estudia los análisis factoriales confirmatorios y la validación externa de la escala. Se obtuvo un instrumento unifactorial de 9 ítems, con una consistencia interna aceptable $(\alpha=.886)$ que sugiere una adecuada aplicabilidad en población general, así como relaciones esperables con variables típicas (ATLG, RWA, SDO y religiosidad).

Palabras clave: actitudes negativas, personas trans, prejuicio sexual, prejuicio de género, ley de identidad de género

Construction and validation of a Negative Attitudes toward Trans People Scale

The study goal was to construct and psychometrically validate a negative's attitudes towards trans people scale (EANT) as an expression of prejudice against trans. Two interdependent sequential studies through questionnaires are reported, both rely on non-probabilistic samples: Study 1, involves 203 participants, mainly college students, addresses the construction and exploratory analysis of the EANT. Study 2, involving 408 participants assigned according to $s$ ociodemographic quotes established by the national census in the general population, shows confirmatory factor analysis and external validation of the scale. A sole factor 9-item instrument, with acceptable internal consistency $(\alpha=.886)$ was obtained.

1 Licenciado en Psicología por la Universidad Nacional de Córdoba. Dirección postal: Facultad de Psicología, Universidad Nacional de Córdoba - Enfermera Gordillo esq. Enrique Barrios, Ciudad Universitaria - CP: 5000, Córdoba - Argentina. Contacto: paezjoseunc@gmail.com

2 Licenciado en Psicología por la Universidad Nacional de Córdova. Contacto: guille_hevia@ hotmail.com

3 Licenciada en Psicología por la Universidad Nacional de Córdova. Contacto: florpesci@ gmail.com

4 Doctor en Psicología y profesor en la Universidad Nacional de Córdova. Contacto: hrabbia@ gmail.com 
The results suggest good applicability in general population studies. Expected relations with typical variables (ATLG, RWA, SDO and religiosity) were procured.

Keywords: Negative attitudes, trans people, sexual prejudice, gender prejudice, trans identity law 
Entre las ideas fundamentales sobre las que se asientan las representaciones de mundo y las subjetividades se encuentra la creencia de que existen solo dos tipos de personas sexuadas: varones y mujeres. Esta dicotomía está tan arraigada en nuestra sociedad y nuestra psique que es ignorada hasta que nos encontramos con alguien cuya membrecía a esta binariedad nos resulta incierta. Las personas trans (travestis, transexuales y transgéneros) rompen con la concepción binaria de género dominante $y$, por ello, se ven expuestas de manera sistemática a diversas formas de hostigamiento, persecución, represión, exclusión y otras prácticas de violencia interpersonal e institucional. Fuertes prejuicios sociales sustentan estas prácticas discriminatorias, legitimadas por figuras médico-legales que han criminalizado, patologizado y estigmatizado las identidades y expresiones de género no heteronormadas ni binarias. Como consecuencia, las personas trans de Argentina se encuentran entre las poblaciones más vulneradas socialmente, según diversas fuentes (Instituto Nacional contra la Discriminación, la Xenofobia y el Racismo [INADI], 2012; Iosa et al., 2012), situación que se replica en otros contextos latinoamericanos (OTD \& IGLHRC, 2012).

El concepto de transgeneridad aborda múltiples experiencias vitales, discursos y categorías identitarias que, "a partir de una concepción a la vez materialista y contingente del cuerpo, la identidad, la expresión de sí, el género y la sexualidad, [rechazan] la diferencia sexual como matriz natural y necesaria de subjetivación” (Cabral, 2011, p. 97). A lo largo de los últimos ańos, en un ciclo de politización de las sexualidades sin precedentes en el país, la denominación "trans" ha adquirido un carácter de marcador político para situar reivindicaciones de sectores usualmente relegados de las políticas LGBTI (lesbianas, gays, bisexuales, trans e intersexuales). Tanto desde demandas más típicas de un paradigma regulatorio de derechos como desde paradigmas libertarios las luchas de las personas trans se han abocado a transformar las actitudes 
sociales hacia las sexualidades diversas y lograr el reconocimiento legal y la efectivización de sus derechos humanos básicos por parte del Estado.

Un hito relevante de estas luchas es la sanción por el Congreso Nacional en mayo de 2012 de la Ley No 26.743 o Ley de Identidad de Género. La legislación tiene el objeto de garantizar a las personas la rectificación registral del sexo, el cambio de nombre de pila e imagen y el acceso a intervenciones quirúrgicas totales y parciales y/o tratamientos integrales hormonales para adecuar su cuerpo, incluida su genitalidad, a su identidad de género auto-percibida, sin necesidad de requerir autorización judicial o administrativa, y totalmente a cargo del Estado Nacional (Boletín Oficial, Ley 26.743, 2012). Sin embargo, de la promulgación de dicha ley no se desprende que las actitudes de prejuicio y discriminación sexual de los/as argentinos/as haya mermado. Tal como sostienen Turizo e Iglesia (2011), las conquistas legales o jurisprudenciales alcanzadas por la comunidad lésbica, gay, trans y bisexual no constituyen per se inmediata aceptación en el ámbito social, ya que la discriminación, los prejuicios o estereotipos negativos contra estas minorías siguen siendo parte del imaginario colectivo e institucional.

Por esta razón la investigación psicológica ha contribuido, y puede contribuir aún más, con la comprensión y explicación del prejuicio hacia personas trans, como lo ha hecho respecto a otras minorías sexuales, étnicas, religiosas o raciales. Para ello se requiere contar con instrumentos de medición psicométricamente adecuados de las actitudes desfavorables hacia personas trans así como mayores evidencias respecto a su relación con variables s ociodemográficas, psicosociales y psicopolíticas en población general.

El objetivo del presente trabajo ha sido construir y validar una escala de actitudes negativas hacia personas trans en Argentina, la cual cuente con evidencias psicométricas y teóricas sustentables y permita la indagación de dichas actitudes en muestras de población general. La meta que ha guiado el trabajo es poder conocer a la vez que generar una propuesta instrumental para desarrollar mediciones periódicas, y lograr así información pertinente para el análisis de las dinámicas actitudinales y la estructuración del prejuicio hacia personas trans, en un contexto 
donde se requiere realizar un seguimiento del reconocimiento social a partir de los avances logrados en términos del reconocimiento legal.

\section{La indagación del prejuicio hacia personas trans y sus factores explicativos}

La investigación sobre actitudes hacia personas travestis, transexuales y transgéneros es relativamente incipiente, a su vez que aún se presenta como escasa, esporádica y asistemática (Claman, 2007; Hill \& Willoughby, 2005; Norton \& Herek, 2012). Tradicionalmente los estudios de prejuicio sexual se han enfocado en estudiar los determinantes o factores explicativos de actitudes negativas en relación con poblaciones gays, lesbianas y, en menor medida, bisexuales, y existen numerosas propuestas de medición de dichas actitudes que gozan de mayor o menor consenso entre los/as estudiosos/as (Castillo, Rodríguez, Torres \& Martel, 2003; Herek, 1988, 2000; Moral de la Rubia, 2010; Wright, Adams \& Bernat, 1999).

Como apunta Hill (2002), la investigación en violencia antitransgénero es especialmente débil debido a la ausencia de un marco conceptual desde el cual entender el odio dirigido hacia esta comunidad. En parte, la predominancia de la agenda política gay y lésbica ha conllevado a la invisibilización de las demandas de personas trans e intersexuales (Cabral, 2011). La evidencia empírica disponible, por su parte, suele adolecer de una falta de uniformidad en los reportes, de muestras no aleatorias y errores en la construcción de instrumentos y análisis de datos. De acuerdo a Norton y Herek (2012), el conocimiento acerca de las actitudes hacia las personas trans es aún muy limitado, resaltando la idea de que es necesario utilizar muestras probabilísticas para obtener una mejor comprensión de las actitudes actuales hacia las personas trans y sus correlatos psicosociológicos en contextos ampliados.

En un esfuerzo por avanzar en el conocimiento de estas actitudes negativas, Norton y Herek (2012) indagaron el prejuicio sexual hacia personas trans en una muestra probabilística a nivel nacional entre adultos 
de EE.UU. Utilizaron para la medición del prejuicio el clásico "termómetro de sentimientos", el cual requiere la auto-ubicación de las personas encuestadas en un eje de cercanía-lejanía respecto a personas trans en una escala de ubicación gráfica que va de 0 a 100. Las puntuaciones más bajas en este termómetro indicaron frío, es decir, actitudes negativas, y las más altas, calor, actitudes más positivas. Si bien la aplicación del termómetro de sentimientos es un avance en la apertura del campo de estudios en relación con actitudes negativas hacia personas trans, y resulta en información de fácil acceso y comparable diacrónicamente, aún es necesario contar con instrumentos más detallados, fiables y sensibles contextualmente que permitan abordar la temática con mayor complejidad.

Probablemente el instrumento más reconocido en la actualidad para indagar las actitudes hacia personas trans sea la Escala de Ideología de Género y Transfobia (GTS, por sus siglas en inglés) propuesta por Hill y Willoughby (2005a). La misma consta de 32 ítems para indagar el rechazo emocional (disgust), violencia, hostigamiento y discriminación hacia personas transgénero, transexuales y travestis. Los autores identifican una triple dimensión del prejuicio antitrans en las dimensiones transfobia, ideología de género (genderism) y hostigamiento de género (gender-bashing), pero la estructura factorial subyacente a la escala admite dos factores: ideología de género/transfobia y hostigamiento de género.

Una versión breve de la GTS fue desarrollada y validada con una muestra de estudiantes españoles por Rodríguez-Castro, LameirasFernández, Carrera-Fernández y Vallejo-Medina (2013); esta versión consta de 12 ítems que contribuyen factorialmente con un 54.22\% de la varianza total. También la escala fue modificada y aplicada en estudiantes universitarios/as estadounidenses/as (Gerhardstein \& Anderson, 2010), australianos/as (Riggs, Webber \& Fell, 2012) y de Hong Kong (Winter, Webster \& Cheung, 2008), entre otros/as.

Los/as autores/as originales de la GTS advierten de posibles problemas de multicolinealidad dada la alta correlación entre la GTS, las medidas de homofobia y de ideología de roles de género, sugiriendo que indagarían constructos muy similares, por lo que la GTS fallaría la prueba 
de validez discriminante. A su vez, los/as autores/as insisten en la necesidad de replicar la escala en poblaciones no académicas para dar cuenta de su validez externa (Hill \& Willoughby, 2005), ya que los estudios que se han relevado se han desarrollado con poblaciones estudiantiles.

Nagoshi y colaboradores (2008) realizaron una serie de críticas a la GTS. Consideran que existen una serie de problemas psicométricos con esta escala, así como lagunas en el establecimiento de la validez de constructo de la medida. Cuestionan que las tres subescalas que estipulan los autores no fueron obtenidas a través de procedimientos analíticos factoriales. Las altas correlaciones entre las tres subescalas (de $r=.73$ a .84) sugieren que no existe validez discriminante entre las mismas. Consideran que Hill y Willoughby (2005) solo tuvieron en cuenta para la redacción de su escala constructos relacionados a la adhesión a roles tradicionales de género y la falta de familiaridad con personas trans en detrimento de un mayor rango de constructos que la literatura en el área sugiere que podrían haber usado, como ser aquellos vinculados a derechos vulnerados y reivindicados por estas personas.

Los autores presumen que una medida más corta y ajustada podría capturar toda la varianza relevante de la escala original. Por ello, proponen una escala de prejuicio hacia personas trans a partir del constructo transfobia de la propuesta original (Nagoshi et al., 2008). La escala, que consta de nueve ítems (con un $\alpha=.82$ ), focaliza en una perspectiva de la transfobia que privilegia componentes emocionales por sobre los cognitivos. La escala fue nominada "Escala de Transfobia" y correlaciona fuertemente y de manera positiva con medidas de homofobia, autoritarismo del ala de derecha (RWA, por sus siglas en inglés), fundamentalismo religioso, sexismo hostil y benevolente, propensión a la agresión, y aceptación del mito de la violación ("rape myth acceptance") (Nagoshi et al., 2008). También se puede advertir que dicha escala solo ha sido validada en poblaciones de estudiantes universitarios, siguiendo vigente la demanda de utilizar muestras de población en general.

Winter y colaboradores (2008) realizaron un estudio transcultural en siete países (China, Malasia, Singapur, Tailandia, Filipinas, Reino Unido y Estados Unidos) examinando percepciones de alumnos universitarios 
en relación con personas trans, en especial mujeres trans, en un continuo de aceptación-prejuicio, con el objeto de indagar los factores subyacentes a este continuo y sus relaciones entre ellos. Utilizan para este fin un cuestionario de treinta ítems concerniente a las mujeres trans, sus características percibidas y sus derechos. Los ítems fueron redactados a partir de experiencias de los autores de trabajo con personas trans, y refieren a creencias acerca de la naturaleza de la identidad de género trans, actitudes hacia el contacto social con mujeres trans y creencias sobre cómo la sociedad debería responder a las personas trans. Este estudio cuenta con algunas limitaciones: no se examina la validez concurrente ni predictiva del constructo, solo se focaliza en percepciones hacia mujeres trans y los participantes no eran representativos de la población nacional de la que fueron extraídos ni tampoco de la universidad a la que pertenecían.

En Suecia, Landén e Innala (2000) examinaron específicamente las actitudes hacia lo que denominan "reasignación de sexo" y hacia las personas transexuales en una muestra aleatoria nacional utilizando un instrumento desarrollado para tal fin: la Encuesta Nacional de Actitudes hacia la Transexualidad. La escala utilizada constó de trece preguntas que examinaron opiniones respecto a esta población, tales como si el/la respondiente considera que la transexualidad es una enfermedad, si muestran acuerdo respecto a que la persona pueda cambiar de nombre, identidad, utilizar hormonas, realizarse una operación quirúrgica, quién debería costear esos gastos, si debieran tener derecho al matrimonio civil, a adoptar niños, trabajar con niños, si el respondiente podría tener una persona transexual como compañero/a de trabajo, como amigo/a, como pareja, y si consideran que los medios prestan demasiada atención a las personas trans. Las indagaciones no se presentan integradas como un único constructo, sino que refieren a distintas cuestiones que algunos autores han indagado de forma autónoma como, por ejemplo, las atribuciones causales de la transexualidad y el contacto social con personas trans.

Más próximo al contexto latinoamericano, Rottenbacher de Rojas (2012) describe y analiza la relación entre la ideología política, la intolerancia a la ambigüedad, la homofobia y el prejuicio hacia grupos 
transgénero en una muestra no aleatoria de estudiantes universitarios de la ciudad de Lima, Perú. Encuentra una relación directa entre estas variables y el prejuicio hacia grupos transgénero. El prejuicio hacia grupos transgénero fue evaluado a través de una escala tipo Likert de 6 puntos, de 1="totalmente positivo" a 6 = "totalmente negativo", donde los/as participantes indicaban qué tan positiva o negativa era la presencia de distintos grupos transgéneros para la sociedad. No encontraron diferencias estadísticas significativas entre varones y mujeres con respecto a la homofobia o el prejuicio hacia grupos transgénero, aunque sí advirtieron una relación positiva más intensa del autoritarismo del ala de derecha (RWA) con el prejuicio hacia grupos trans respecto a la orientación de dominancia social (SDO).

Además de las creencias o estereotipos de roles de género, la homofobia o actitudes hacia personas gays y lesbianas, el RWA y la SDO, otras variables psicosociales, sociodemográficas y de religiosidad han mostrado poder explicativo de las actitudes hacia personas trans. Las personas que presentan actitudes más desfavorables hacia personas trans, cualquiera sea la medición utilizada para su indagación, tienden a ser más varones que mujeres (Carrera-Fernández et al., 2013; Claman, 2007; Hill \& Willoghby, 2005; Kooy, 2010; Landen \& Innala, 2000); de mayor edad (Landén \& Innala, 2000) —aunque Norton y Herek no advirtieron una relación significativa entre edad y prejuicio hacia personas trans-; de menor nivel socioeconómico (Norton \& Herek, 2012), y con altos niveles de religiosidad (Claman, 2007; Norton \& Herek, 2012; Willoughby et al., 2010) o en fundamentalismo religioso (Nagoshi et al., 2008).

También las personas heterosexuales presentan actitudes más negativas hacia personas trans que las personas gays y lesbianas (Willoughby et. al., 2010), lo cual podría constituir un indicador fiable de que la medición de las actitudes hacia personas trans integra el campo de indagaciones de prejuicios integrupales. A partir de lo que Norton y Herek (2012) denominan "hipótesis de transferencia", se ha sugerido que la estructuración del prejuicio hacia personas trans es similar a la del prejuicio hacia gays y lesbianas. No obstante, no se cuentan con evidencias suficientes en el contexto local que permitan avalar o descartar 
estos postulados. En síntesis, se advierte aún la necesidad de desarrollar instrumentos teórica y psicométricamente adecuados para indagar el prejuicio hacia personas trans que permitan una mejor comprensión de la especificidad de estas actitudes, así como el desarrollo de estudios que consideren las tendencias y transformaciones en las dinámicas actitudinales a la luz de acontecimientos sociopolíticos resonantes para la política sexual que encarnan las personas trans.

A continuación se describen los dos estudios consecutivos a partir de diseños cuantitativos realizados con personas residentes de la ciudad de Córdoba, Argentina, con el objetivo de construir y validar una escala de actitudes negativas hacia personas trans.

\section{Estudio 1}

El objetivo principal del primer estudio fue elaborar y testear un conjunto inicial de ítems para la indagación de las actitudes hacia las personas trans en pos de construir un instrumento adecuado teórica y psicométricamente para su medición. Con ese fin se realizaron se realizaron análisis descriptivos, análisis factorial exploratorio, análisis de confiabilidad y de validación externa.

\section{Método}

\section{Participantes}

Los/as participantes fueron residentes en la ciudad de Córdoba de entre 18 y 65 años de edad, seleccionados a través de un muestreo no aleatorio accidental. El total de participantes fue de 203 personas con una edad promedio de 27.77 años. Del total de participantes, 130 se auto identificaron como mujeres y 73 varones; en su mayoría fueron estudiantes universitarios/as o vinculados/as laboralmente al sector académico, ya que el cuestionario se aplicó en las inmediaciones de la ciudad universitaria local. 


\section{Medidas e instrumentos de medición}

A los fines de disponer de un instrumento que indagara las actitudes hacia personas trans se testeó una propuesta integrada por 22 reactivos redactados tanto en sentido positivo y negativo los cuales fueron construidos teniendo en cuenta los aportes de los antecedentes teóricos que han instrumentalizado diversas propuestas de medición de actitudes hacia personas trans, transfobia y prejuicio sexual en general. Ítems como "Está bien que las personas trans puedan adoptar niños", "Las personas trans no deberían poder enseñar en las escuelas", "Las personas trans no deberian ser integradas en nuestra sociedad" resultan adaptaciones de reactivos que Herek (1988) utiliza en su escala ATGL. También se consideró la Escala de Actitudes de Heterosexuales hacia Homosexuales (HATH) (Larsen, Reed \& Hoffman, 1980) en ítems tales como "Deberia restringirse el ingreso de personas trans a bares y boliches", "Las personas trans no deberian tener los mismos derechos que el resto de la sociedad". Las afirmaciones debían responderse con una escala tipo Likert de 5 puntos, yendo de 1 = totalmente en desacuerdo a 5 = totalmente de acuerdo. Mayores puntajes en la escala agregada son indicadores de mayores niveles de actitudes negativas hacia personas trans.

Los puntajes de los ítems redactados en sentido positivo que se incorporaron a los análisis definitivos fueron invertidos a fin de mantener una estructura coherente del puntaje agregado de la escala. Cabe destacar que se utilizó en algunos ítems de forma indistinta la denominación "travesti", "transgénero", "transexual" o "trans", dado que resultó en una mejor comprensión por parte de las personas entrevistadas. Somos conscientes de que las nociones "travesti", "transgénero" o "transexual" no refieren a las mismas características ni resultan en auto identificaciones unívocas por parte de las personas, pero el concepto "trans" parece haberse introducido en el sentido común de los/as cordobeses/as como un concepto que los engloba a la vez que los homogeniza.

De igual forma se indagaron cuatro reactivos dirigidos hacia la población homosexual basados en ítems de la escala breve ATGL de Herek (1988) que funcionaron a modo de control, dado que se 
desconocía de antemano el grado de conocimiento de las personas participantes del estudio respecto a lo que implica la noción trans. Dichos reactivos se utilizaron como medida de control y para la validación externa de la escala.

Se incluyeron a su vez indagaciones sociodemográficas, respecto a la ocupación actual, la carrera en estudio en caso de ser estudiante, así como la edad, el sexo asignado al nacer, el máximo nivel educativo alcanzado, y la orientación del deseo e identidad de género y sexual, la cual se reportó a partir de la autoidentificación de la persona con alguna de las siguientes categorías: $1=$ Heterosexual, $2=$ Gay, $3=$ Lesbiana, $4=$ Bisexual, $5=$ Travesti, $6=$ Transexual, $7=$ Transgénero y $8=$ Otra, para la cual debían detallar cuál. También se incluyó la opción NS/NC, aunque fueron pocos los casos que no se auto-identificaron.

También se incluyeron mediciones típicas de religiosidad personal, como ser la religión de pertenencia actual, la frecuencia de asistencia al culto y la intensidad del sentimiento religioso, según la escala propuesta por Grasmick, Cochran, Bursik Jr. y Kimpel (1993), y validada para el contexto local por Lista (1995). Esta última escala incluyó cinco ítems, que refieren a la importancia percibida de la religión, la influencia religiosa percibida en la propia vida, la autopercepción de religiosidad, el dogmatismo u obligación religiosa percibida y un ítem sobre la influencia percibida de la religión en las decisiones familiares, respondiéndose con una escala tipo Likert de 5 puntos de $1=$ totalmente en desacuerdo a 5 = totalmente de acuerdo. De forma agregada, la escala quedó conformada por un puntaje de 5 a 25 puntos, siendo que el menor puntaje representó una nula intensidad del sentimiento religioso y el mayor, alta intensidad del sentimiento religioso. La escala arrojó una buena consistencia interna $(\alpha=868)$.

\section{Procedimiento}

Se aplicó un cuestionario estructurado de forma autoadministrada, el cual tuvo una duración promedio de 20 minutos. Se recogió el consentimiento informado de los/as participantes, tras notificarles el objetivo y alcance del estudio y garantizar las condiciones de confi- 
dencialidad, anonimato, y de utilización de la información con fines exclusivamente académicos. Las personas podían abandonar el cuestionario siempre que así lo decidieran, aunque la tasa de abandono fue baja y por tanto se procedió a retomar los casos para alcanzar los $\mathrm{N}$ previamente establecidos. Los datos recogidos se cargaron en sendas bases de datos diseñadas a tal fin a partir de las opciones brindadas por el software SPSS 19, a partir de la cual se desarrollaron los análisis detallados para cada muestra.

\section{Análisis de datos}

En un primer momento se obtuvieron las medias, frecuencias, análisis de valores perdidos, y coeficientes de asimetría y curtosis de todos los ítems de las escalas utilizadas en el cuestionario. Los valores perdidos detectados por el sistema fueron imputados por la media ya que no superaban el $5 \%$ de los casos disponibles y no se advirtió un patrón aleatorio en los mismos. Los índices de asimetría y curtosis fueron útiles para obtener datos sobre el supuesto de normalidad de las respuestas, necesario para realizar análisis multivariados e identificar la robustez de los reactivos propuestos. A tal fin, se consideraron valores entre $\leq 1.00$ como resultados excelentes y valores entre $\leq 2.00$ como adecuados (George \& Mallery, 2011). En algunos casos, se inspeccionó el histograma con curva normal para analizar la distribución de las respuestas en ítems específicos. En los casos en que la curva se distribuía de forma asimétrica o "en peine" (Luijk, 2010), se reevaluó teóricamente la pertinencia - o no- de los ítems analizados. Se consideraron también las referencias de los/as propios/as entrevistados/as, en función de evaluar el nivel de comprensión de los ítems desarrollados.

A través de un análisis factorial exploratorio (AFE) se procedió a indagar la dimensionalización de la escala elaborada de actitudes hacia personas trans. Se solicitó el índice $\mathrm{KMO}$ como así también los niveles de significación, utilizando el método de componentes principales con rotación Varimax, el más adecuado para establecer diferenciaciones en la estructura subyacente de escalas (Morales Vallejo, 2013). Se consideró el gráfico de sedimentación como uno de los criterios para la identificación 
de conglomerados o factores de la estructura. A su vez se consideró como autovalor .35 al momento de fijar el límite mínimo de saturación factorial. En aquellos casos en que un ítem saturase en dos o más factores se decidió ubicarlo en aquel en el que presentase una saturación mayor a .10 de diferencia respecto del/los otro/s factor/es, siempre acompañando este tipo de decisión con criterios teóricos que la respalden. Respecto a los ítems que presentaron una saturación similar en dos o más factores, se procedió a eliminarlos de los análisis posteriores por no brindar evidencias de una adecuada dimensionalización, acompañado también de criterios teóricos. Posteriormente se realizaron correlaciones bivariadas inter-ítem para poder observar el grado y el sentido de las relaciones existentes entre los mismos, y se consideraron válidas aquellas que no reflejaran un $r \geq .90$, para evitar problemas de multicolinealidad (Tabachnick \& Fidell, 2001).

Se llevaron a cabo análisis de confiabilidad y consistencia interna de los ítems retenidos por el análisis factorial, tanto de forma agregada (todos los ítems), como solicitando los Alphas en caso de eliminar algún elemento de la escala. En caso de que el Alpha aumentara considerablemente al eliminar algún ítem, y no afectara los fundamentos teóricos de la escala, se sugirió su eliminación. Finalmente, para indagar la validez externa de la escala resultante se realizaron correlaciones bivariadas simples con las variables independientes, en particular, edad, educación, frecuencia de asistencia al culto e intensidad del sentimiento religioso, así como respecto a dos de los ítems sondeados sobre actitudes hacia personas homosexuales en general. A tal fin se consideró el índice de correlación de Pearson, considerando como débiles, moderados o fuertes los valores habituales consensuados por la literatura (Elorza Pérez-Tejada, 2008).

\section{Resultados}

En primer término se inspeccionaron las respuestas para cada ítem, así como las referencias de los/as participantes respecto a la comprensión de los mismos. Algunos ítems fueron eliminados de análisis posteriores debido a que durante la toma de los cuestionarios, algunos/ 
as participantes manifestaron confusión respecto de la interpretación y la direccionalidad de los reactivos. Ejemplo de este caso lo constituye el reactivo: Las personas trans eligen la prostitución como fuente de trabajo, que no brindó evidencias de una correcta dimensionalización teórica. También se resolvió eliminar los ítems que fueran similares respecto de su construcción semántica, privilegiándose mantener aquellos que poseían una direccionalidad negativa explícita y una mayor concreción del objeto actitudinal y una mejor dimensionalización teórica, la cual suele ser privilegiada en los instrumentos sobre prejuicio: por ejemplo, el ítem cualquier trabajo puede ser desempeñado por una persona trans fue reemplazado por el ítem las personas trans no deberian poder enseñar en las escuelas. La eliminación de algunos ítems resultaba pertinente en función de poder contar con una escala con menor cantidad de ítems que fuera más accesible para un estudio con población en general.

Seguidamente, se obtuvieron los índices de asimetría y curtosis (ver Tabla 1) de los ítems considerados. Del total de ítems analizados, once presentaron valores excelentes o adecuados de asimetría y curtosis, mientras que igual número presentó valores que excedían los recomendados por George y Mallery (2011). Reactivos que suponen una alta penalización o prácticas de discriminación manifiesta hacia personas trans, como ser La leyes deberian ser más duras con las personas travestis, transexuales y transgéneros o Debería restringirse el ingreso de personas trans a bares $y$ boliches, mostraron un rechazo claramente mayoritario de la muestra, por lo cual no permiten una adecuada dimensionalización y debieron ser eliminados de análisis posteriores. En igual sentido, se comportaron los reactivos negativos más genéricos como Las personas trans no deberian ser integradas en la sociedad o Las personas trans son malas para nuestra sociedad porque rompen la división natural entre los sexos, y aquellos que refieren a cuestiones de intersección entre las actitudes hacia personas trans y aspectos religiosos, como las personas trans deberian tener prohibida la entrada a las Iglesias o Las personas trans son pecadoras. Es posible que este último aspecto se deba a que los niveles de intensidad religiosa de la muestra fueron considerablemente más bajos que los documentados para la población general ampliada (Ver Tabla 1). 


\section{Tabla 1}

Descriptivos de los items propuestos para la Escala de actitudes negativas hacia personas trans ( $n=173$ heterosexuales)

\begin{tabular}{|c|c|c|c|c|}
\hline Descriptivos & $M$ & $D E$ & Asimetria & Curtosis \\
\hline $\begin{array}{l}\text { Está bien que las personas trans puedan adop- } \\
\text { tar niños (R) }\end{array}$ & 2.84 & 1.51 & .106 & -1.459 \\
\hline $\begin{array}{l}\text { Las personas trans no deberían poder enseñar } \\
\text { en las escuelas }\end{array}$ & 1.88 & 1.330 & 1.289 & .296 \\
\hline El sexo con una persona trans no es natural & 2.45 & 1.553 & .518 & -1.291 \\
\hline $\begin{array}{l}\text { Las personas trans son una amenaza para la } \\
\text { familia y la sociedad }\end{array}$ & 1.67 & 1.230 & 1.677 & 1.467 \\
\hline $\begin{array}{l}\text { Las personas trans tienden a ser sexualmente } \\
\text { promiscuas }\end{array}$ & 2.41 & 1.243 & .317 & -.888 \\
\hline $\begin{array}{l}\text { Sería chocante ver a una persona trans dando } \\
\text { un beso }\end{array}$ & 2.43 & 1.499 & .486 & -1.281 \\
\hline Me molestaría que un hijo mío sea travesti & 2.96 & 1.523 & -.051 & -1.460 \\
\hline $\begin{array}{l}\text { Las personas trans son más propensas que el } \\
\text { resto de la sociedad a contraer una enfermedad } \\
\text { sexual }\end{array}$ & 2.60 & 1.450 & .213 & -1.418 \\
\hline $\begin{array}{l}\text { Los travestis son homosexuales disfrazados de } \\
\text { mujer }\end{array}$ & 2.43 & 1.468 & .467 & -1.185 \\
\hline $\begin{array}{l}\text { Reconocer a personas trans como normal sería } \\
\text { algo beneficioso para nuestra sociedad (R) }\end{array}$ & 2.24 & 1.367 & .743 & -.703 \\
\hline $\begin{array}{l}\text { Evito a las personas trans siempre que me es } \\
\text { posible }\end{array}$ & 1.89 & 1.331 & 1.207 & 0.68 \\
\hline Pienso que las personas trans son repugnantes & 1.60 & 1.114 & 1.784 & 2.176 \\
\hline $\begin{array}{l}\text { Las personas trans no deberían ser integradas } \\
\text { en la sociedad }\end{array}$ & 1.31 & .912 & 3.151 & 9.246 \\
\hline $\begin{array}{l}\text { Las personas trans son malas porque rompen la } \\
\text { división natural entre los sexos }\end{array}$ & 1.62 & 1.197 & 1.851 & 2.133 \\
\hline Las personas travestis son pecadoras & 1.59 & 1.151 & 1.850 & 2.233 \\
\hline $\begin{array}{l}\text { Debería restringirse el ingreso de personas trans } \\
\text { a barres y boliches }\end{array}$ & 1.39 & 1.015 & 2.744 & 6.520 \\
\hline $\begin{array}{l}\text { Las personas trans no deberían tener los mis- } \\
\text { mos derechos que el resto de la sociedad }\end{array}$ & 1.35 & .912 & 2.879 & 7.774 \\
\hline $\begin{array}{l}\text { Si se descubre que un empleado se trasviste } \\
\text { debería ser despedido }\end{array}$ & 1.34 & .886 & 2.983 & 8.413 \\
\hline
\end{tabular}




\begin{tabular}{|c|c|c|c|c|}
\hline Descriptivos & $M$ & $D E$ & Asimetria & Curtosis \\
\hline $\begin{array}{l}\text { Está bien que las personas trans puedan adop- } \\
\text { tar niños (R) }\end{array}$ & 2.84 & 1.51 & .106 & -1.459 \\
\hline $\begin{array}{l}\text { Las personas trans no deberían poder enseñar } \\
\text { en las escuelas }\end{array}$ & 1.88 & 1.330 & 1.289 & .296 \\
\hline El sexo con una persona trans no es natural & 2.45 & 1.553 & .518 & -1.291 \\
\hline $\begin{array}{l}\text { Las personas trans son una amenaza para la } \\
\text { familia y la sociedad }\end{array}$ & 1.67 & 1.230 & 1.677 & 1.467 \\
\hline $\begin{array}{l}\text { Las personas trans tienden a ser sexualmente } \\
\text { promiscuas }\end{array}$ & 2.41 & 1.243 & .317 & -.888 \\
\hline $\begin{array}{l}\text { Sería chocante ver a una persona trans dando } \\
\text { un beso }\end{array}$ & 2.43 & 1.499 & .486 & -1.281 \\
\hline Me molestaría que un hijo mío sea travesti & 2.96 & 1.523 & -.051 & -1.460 \\
\hline $\begin{array}{l}\text { Las personas trans son más propensas que el } \\
\text { resto de la sociedad a contraer una enfermedad } \\
\text { sexual }\end{array}$ & 2.60 & 1.450 & .213 & -1.418 \\
\hline $\begin{array}{l}\text { Las personas trans deberían ser confinadas en } \\
\text { un establecimiento que trate específicamente su } \\
\text { patología }\end{array}$ & 1.52 & 1.134 & 2.067 & 2.997 \\
\hline $\begin{array}{l}\text { Las personas trans deberían tener prohibida la } \\
\text { entrada a las iglesias }\end{array}$ & 1.42 & 1.057 & 2.493 & 5.081 \\
\hline $\begin{array}{l}\text { Las leyes deberían ser más duras con las perso- } \\
\text { nas travestis y transexuales }\end{array}$ & 1.32 & .901 & 2.998 & 8.413 \\
\hline $\begin{array}{l}\text { Me niego a llamar a una persona trans por el } \\
\text { nombre que utiliza porque no se corresponde } \\
\text { con el sexo con el que nació }\end{array}$ & 1.60 & 1.185 & 1.868 & 2.240 \\
\hline
\end{tabular}

Nota: se presentan los valores de asimetría y curtosis de los ítems que finalmente componen la escala de actitudes negativas hacia personas trans. (R): puntaje revertido.

A continuación se realizó un análisis factorial exploratorio siguiendo los criterios establecidos anteriormente. Los ítems Reconocer las identidades trans como normal sería beneficioso para nuestra sociedad y Evito a las personas trans siempre que me es posible fueron eliminados porque saturaban en dos factores con valores casi idénticos, siendo los únicos ítems que saturaban también en un segundo factor. En esta decisión se contempló también que la inclusión o eliminación de algún reactivo estuviera acorde a lo esperable en términos teóricos. Considerando estos criterios, así como la exploración visual del gráfico 
de sedimentación que sugería un único factor principal, se obtuvo finalmente una solución unidimensional compuesta por 9 elementos que explican el $52.57 \%$ de la varianza total con un $\mathrm{KMO}=.884$, siendo $p \leq 0.01$ (Ver Tabla 2).

\section{Tabla 2}

Saturación factorial de los items de la EANT en la muestra del estudio instrumental $(n=173)$

AF Cargas factoriales en

Componente

Está bien que las personas trans puedan adoptar hijos (R)

Las personas trans no deberían poder enseñar en las escuelas

El sexo con una persona trans no es natural

Las personas trans son una amenaza para la familia y la sociedad

Las personas trans tienden a ser sexualmente promiscuas

Seria chocante ver a una persona trans dando un beso

Me molestaría que un hijo mío sea travesti

Las personas trans son más propensas que el resto de la sociedad a contraer una enfermedad sexual

Los travestis son homosexuales disfrazados de mujer

.738

.725

.743

.696

.746

.799

.715

.661

.696 $\alpha$ si ítem es eliminado
.871 .873 .871 .876 .872 .865 .874 .879 .875

Nota: contempla solo participantes auto identificados como heterosexuales.

Si bien algunos reactivos parecen referir más a una valoración genérica de las personas trans (son una amenaza para la familia y la sociedad, por ejemplo), o a concepciones etiológicas (los travestis son homosexuales disfrazados de mujer), mientras otros reactivos apuntan a indagaciones más típicas de disgusto y rechazo (Me molestaría que un hijo mio sea travesti o Sería chocante ver a una persona trans dando un beso), los ítems guardan una coherencia teórica en términos de representar actitudes prejuiciosas hacia personas trans. Como puede observarse, la eliminación de cualquiera de los ítems no reviste una mejora de la fiabilidad interna de la escala, la cual fue de $\alpha=.886$. El análisis de la correlación inter-ítems 
de los reactivos obtenidos del análisis factorial reveló valores entre .32 y .70 , siendo mayores las correlaciones entre los ítems que hacen referencia a aspectos genéricos entre sí, y menores los valores de las correlaciones entre los ítems más genéricos y aquellos con fraseos de evaluación más específicos.

Con el objetivo de validar externamente la escala diseñada se realizaron correlaciones bivariadas entre la escala de actitudes negativas hacia personas trans y las variables edad, nivel educativo, frecuencia de asistencia al culto, intensidad del sentimiento religioso y dos ítems dirigidos hacia la población homosexual. Los resultados obtenidos (ver Tabla 3) reflejan que la edad presenta una correlación positiva débil $(r=.260)$, y que el nivel educativo presenta una correlación negativa muy débil $(r=-.191)$, con la escala de actitudes negativas hacia personas trans. Esto implica que las personas de mayor edad y de menor nivel educativo tenderían a sostener actitudes más negativas hacia las personas trans, en consonancia con lo relevado por nuestros antecedentes. En lo relativo a las variables religiosas, la frecuencia de asistencia a las ceremonias del culto presentó una correlación positiva débil respecto a la variable dependiente $(r=.313)$, lo cual indica que las personas participantes que más frecuencia de asistencia al culto manifestaron son las que presentaron mayor nivel de actitudes negativas hacia personas trans. En el mismo sentido, la escala de actitudes negativas hacia personas trans respecto de la intensidad del sentimiento religioso, presentó una correlación positiva media $(r=.428)$, en línea con lo esperable teóricamente.

Las correlaciones entre la escala de actitudes negativas hacia personas trans y Me produce rechazo ver a dos hombres besándose indican que existe una relación positiva fuerte $(r=.769)$ señalando que las personas que tienen mayor puntaje en este reactivo, poseen un mayor nivel de actitudes negativas hacia personas trans. Resultados similares se encontraron respecto de la escala trans con los homosexuales son enfermos mentales al reportar una relación significativa más moderada entre las mediciones $(r=.548)$. Estos dos últimos indicadores resultan ilustrativos de las concepciones de rechazo y prejuicio sexual y, por ende, permiten sostener que la escala de actitudes negativas hacia personas trans remite a mediciones similares, aunque hacia un diferente objeto actitudinal (personas trans, en este caso). 


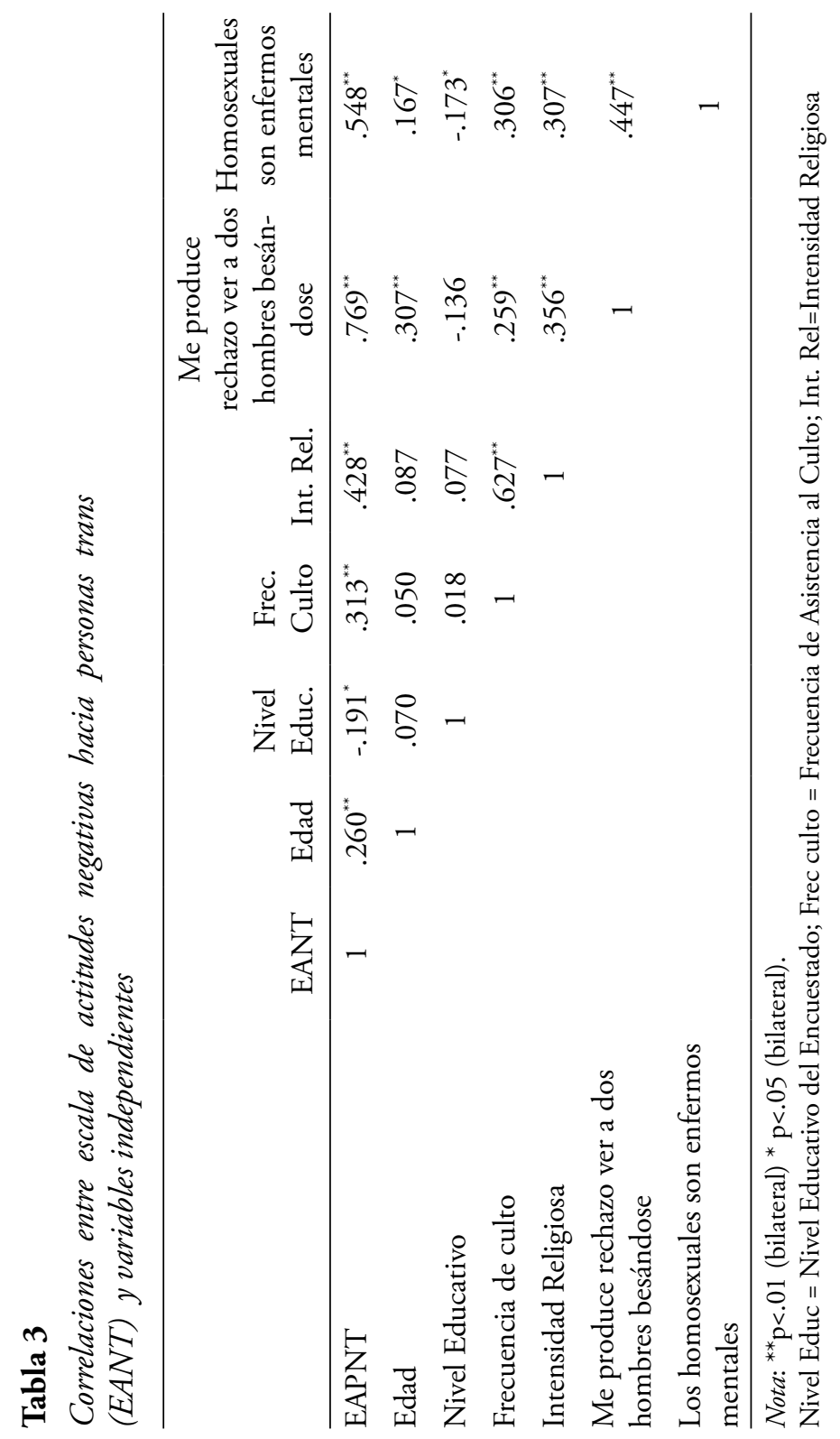




\section{Estudio 2}

Con el objetivo de avanzar en la validación de la escala de actitudes negativas hacia personas trans en población general, se realizaron análisis descriptivos, análisis factorial confirmatorio y análisis de comparación de medias.

\section{Método}

\section{Participantes}

Las personas participantes del estudio fueron seleccionadas a través de un muestreo no aleatorio estratificado por cuotas de edad, nivel socioeconómico y sexo asignado al nacer de entre residentes en la Ciudad de Córdoba de 18 a 65 años. La muestra quedó confeccionada por 410 personas, de las cuales 198 fueron varones y 212 mujeres; con una media de edad de $M=37.52$ años $(D E=13.43)$. Se optó por un muestreo de este tipo dado que permite mejorar las condiciones de un típico muestreo no aleatorio, aunque no se elimina el sesgo de selección; a la vez que garantiza que la muestra esté conformada por proporciones relativas a las distintas características demográficas de la población (Lohr, 2000). Las cuotas de edad, sexo y nivel socioeconómico se establecieron según las proporciones estimadas por el Instituto Nacional de Estadística y Censos (INDEC, 2011) para la ciudad de Córdoba y, en lo relativo al nivel socioeconómico (NSE), las cuotas se ajustaron a los criterios de indagación propuestos por la Comisión de Enlace Institucional de AAM, SIEMPRO y CEIM (2006).

\section{Instrumentos}

Escala de actitudes negativas hacia personas trans: se relevaron los nueve reactivos obtenidos del estudio 1 . Los mismos se reprodujeron en el mismo orden en que se sondearon previamente, y las opciones de respuesta para cada ítem fueron iguales: de 1 (totalmente en desacuerdo) a 5 (totalmente de acuerdo). 
Escala de Orientación hacia la Dominancia Social (SDO): se utilizó una versión de la Escala de Orientación hacia la Dominancia Social (Pratto, et. al., 1994) adaptada por Jaume y colaboradores (2011) al contexto local. Esta se compone de 10 ítems utilizando un formato de respuesta tipo Likert de 5 puntos que van desde $1=$ Totalmente en desacuerdo a 5 = Totalmente de acuerdo y cuenta con 5 reactivos para la dimensión de Oposición a la Igualdad como por ejemplo La igualdad entre personas debe ser nuestro ideal, y 5 reactivos para la dimensión Dominancia Grupal, por ej. Todos los grupos superiores deberian dominar a los inferiores, De acuerdo al estudio realizado por Jaume y colaboradores (2011) la escala presenta indicadores de consistencia bajos de forma global ( $\alpha=.31$ para la escala total) que mejoran en sus dimensiones por separado: Oposición a la igualdad $(\alpha=.55)$ y Dominancia Grupal ( $\alpha$ =.61). Puntajes altos en esta escala, darían cuenta de una mayor Orientación hacia la Dominancia Social. Se utilizó únicamente a dimensión de Dominancia Grupal de la variable (SDO DG en los análisis), debido a que presentó mejores índices estadísticos que la dimensión de Oposición a la Igualdad y la escala en su forma global.

Autoritarismo de Ala Derecha (RWA, por sus siglas en inglés): se utilizó una adaptación de la versión española de la escala de la RWA (Seoane \& Garzón, 1992) desarrollada por Imhoff y Brussino (2012). La escala cuenta con 10 reactivos, por ejemplo, La verdadera clave para una vida digna es la obediencia, la disciplina y ajustarse a lo que está establecido, entre otros, a los que los individuos deben responder de acuerdo a una escala tipo Likert en la que 1 = totalmente en desacuerdo y 5 = totalmente de acuerdo. La escala presenta una estructura factorial unidimensional e indicadores psicométricos satisfactorios $(\alpha=.89)$. La adaptación realizada en el contexto local por Imhoff y Brussino (2012) no contiene la dimensión de convencionalismo de la escala original.

También se indagaron las mismas variables sociodemográficas (edad, nivel educativo, sexo asignado al nacer, orientación del deseo e identidad sexual y de género), así como variables de religiosidad (religión de pertenencia, frecuencia de asistencia al culto e intensidad del sentimiento religioso) que en el estudio 1. La escala de intensidad del 
sentimiento religioso reflejó una buena consistencia interna $(\alpha=.86)$. A fines de avanzar en su validación externa, se indagó también la escala de actitudes hacia personas gays y lesbianas (ATLG, por sus siglas en inglés) en su versión breve propuesta por Herek (1988, 1994), la cual consta de tres ítems que indagan el prejuicio sexual hacia varones gays y los mismos tres ítems con un fraseo orientado hacia lesbianas. Cada ítem se respondía con una escala de 5 puntos, siendo $1=$ totalmente en desacuerdo y $5=$ totalmente de acuerdo. El puntaje agregado de la escala fue de 5 a 25 puntos, indicando el mayor puntaje un mayor prejuicio sexual, siendo $M=17.11, D E=7.79$, con buena consistencia interna $(\alpha=.89)$.

En el estudio se incorporó a su vez una indagación dicotómica respecto a si la persona había oído hablar de la noción trans, a la vez que se les pidió a los/as participantes que refirieran con sus palabras qué entendían por dicha noción. También se indagó el contacto y la proximidad social, a partir de preguntar si conocían o no a persona/s trans y si la/s misma/s era/n familiar directo, amigo/a, vecino/a, compañero/a de trabajo u otra persona.

\section{Procedimiento}

Para la indagación de los datos en el estudio 2 se aplicó un cuestionario semiestructurado administrado con un promedio de duración de 40 minutos. Se siguieron las normas éticas y de confidencialidad referenciadas en el estudio 1.

\section{Análisis de datos}

En primer término, se sometieron a los datos a un análisis de valores perdidos en igual sentido que lo destacado para el estudio 1 . No se advirtieron tampoco valores perdidos que superaran el $5 \%$ de respuestas, ni que representaran patrones aleatorios, por lo cual, se imputó por la media los valores perdidos de los ítems de la escala de actitudes negativas hacia personas trans. Además, se exploraron las respuestas en forma descriptiva, incluyendo valores de media, desviación típica, 
asimetría y curtosis. A su vez, se realizaron análisis de confiabilidad interna, según los criterios previamente establecidos. También se realizaron análisis específicos, a saber:

Análisis Factorial Confirmatorio (AFC): se trabajó con un análisis factorial confirmatorio sobre la escala de actitudes negativas hacia personas trans para corroborar los resultados obtenidos en el factorial exploratorio realizado en el estudio 1. Para considerar el ajuste del modelo como aceptable se tuvieron en cuenta una serie de índices entre los que se encuentran el $X^{2}$, el cual es sensible al tamaño de la muestra e indica la discrepancia entre el modelo elaborado y la covarianza de los datos (Pérez, Medrano \& Sánchez Rosas, 2013); y la razón entre este índice y los grados de libertad del modelo (CMIN/DF), siendo un valor menor a 3.00 un indicador de un buen ajuste del modelo (Pérez et al., 2013). También se consideró el índice de bondad del ajuste (AGFI) en el que valores mayores a .90 sugieren un ajuste aceptable y valores superiores a .95 indican un ajuste excelente (Jöreskog \& Sörgom, 1993, citado en Mola, Saavedra, Reyna \& Belaus, 2013). El índice de ajuste comparativo (CFI) también fue tenido en cuenta para evaluar el ajuste del modelo, en el que valores que superaban .95 indicaban un ajuste aceptable mientras que valores que descendían de .90 eran indicio de re ajustar el modelo y el índice de error cuadrático de aproximación (RMSEA) en el que valores menores a .05 indican un buen ajuste, mientras que valores entre .05 y .08 son considerados aceptables (Ferrando \& Anguiano-Carrasco, 2010). Por último, se tuvieron en cuenta los índices de modificación, los valores de cambio y los coeficientes de regresión estandarizados en el momento de realizar los ajustes al modelo. El AFC se realizó con el software estadístico Amos, compatible con SPSS .19.

Comparación de medias: con el objetivo de identificar las diferencias en las respuestas entre personas auto-identificadas como heterosexuales y personas que se auto-identificaron como gays, lesbianas, trans o no heterosexuales, y validar así, en términos de prejuicio inter grupal, la propuesta de la escala de actitudes negativas hacia personas trans, se realizó un análisis comparativo de medias para muestras 
independientes según el método de $t$ de Student, considerando que la razón $F$ sea estadísticamente significativa, así como la comparación de las medias (M) obtenidas, y las desviaciones estándares como indicadores descriptivos de la varianza (Morales Vallejo, 2011). Dicho análisis se replicó a fines descriptivos para identificar diferencias de sexo en dicha escala (las cuales suelen reportar diferencias entre varones y mujeres en la literatura específica), obteniéndose resultados esperables en términos teóricos, aunque los mismos no se reportan en el presente trabajo.

\section{Resultados}

En primer término cabe destacar que los valores de asimetría y curtosis de los ítems relevados en el estudio 2, fueron adecuados, no registrándose ningún valor superior a \pm 1.60 , incluso por debajo del valor criterio límite fijado por la literatura. En la muestra con población ampliada, los reactivos reflejaron una distribución de respuestas más normal que en el estudio 1, lo cual resultaba esperable.

A continuación, se llevó a cabo un análisis factorial confirmatorio en el cual se trabajó con el modelo de máxima verosimilitud y se solicitaron los índices de modificación, los estimados estandarizados, los efectos totales directos e indirectos y estimaciones de las covarianzas.

Se mantuvieron los 9 ítems seleccionados en la muestra 1 y los enlaces entre el e1 y e7 (Está bien que las personas trans puedan adoptar niños y Me molestaría que un hijo mio sea travesti respectivamente), los errores e2 y e4 (Las personas trans no debería poder enseñar en las escuelas y Las personas travestis son una amenaza para la familia y la gente decente) y e8 y e9 (Las personas trans son más propensas que el resto de la sociedad de contraer una enfermedad sexual y Los travestis son homosexuales disfrazados de mujer), que sugirieron los índices de modificación del modelo. La estructura factorial obtenida presentó un valor de la razón del estadístico $X^{2}$ y los grados de libertad considerado óptimo $\left(\mathrm{CMIN} / \mathrm{DF}=2.103 ; D F=24, X^{2}=50.48\right)$, un índice de bondad de ajuste excelente $(A G F I=.951)$, índice de ajuste comparativo 
excelente $(\mathrm{CFI}=.983)$, y un índice de error cuadrático aceptable $($ RMSEA = .052). Las estimaciones de las contribuciones de los reactivos fueron significativas y aceptables (de .40 a .73). (Ver Figura 1)

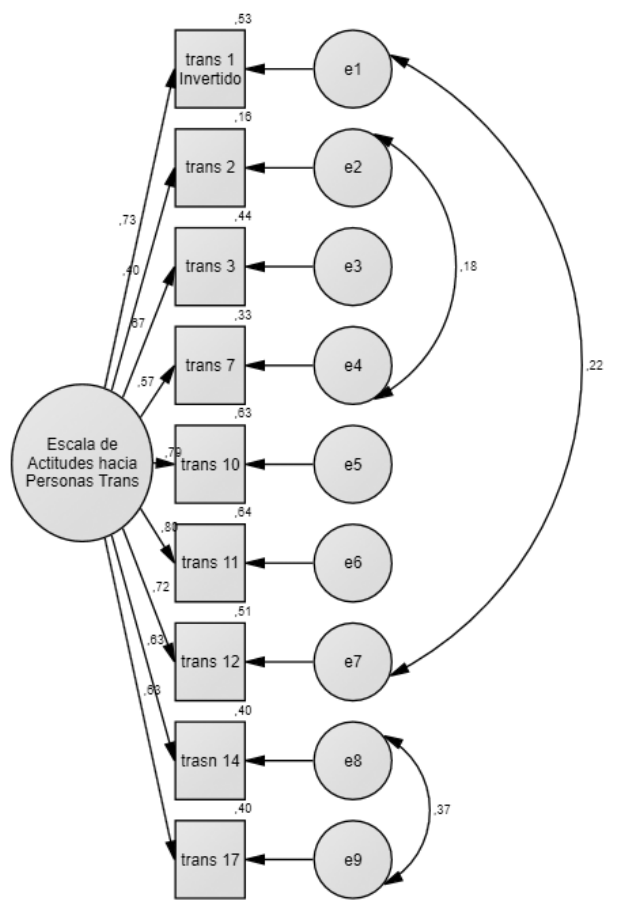

Figura 1. Estructura interna de la EANT obtenida a través de un análisis factorial confirmatorio

Posteriormente se realizó un análisis de fiabilidad para conocer la consistencia interna de la escala a través del Alpha de Cronbach, solicitando los indicadores estadísticos para el elemento, la escala y la escala si se elimina algún elemento. Se obtuvo un $\alpha=.886$ el cual es considerado un índice aceptable y la eliminación de cualquier elemento no contribuía a mejorar la consistencia interna de la escala (Ver Tabla 4). A su vez, la correlación ítem total fue aceptable (entre .54 y .71) a 
excepción del reactivo Las personas trans no deberian poder enseñar en las escuelas, que fue de .38. No obstante, se consideró pertinente retener este reactivo en la escala, dada las evidencias de los análisis instrumentales, los análisis factoriales en la presente muestra y las contribuciones teóricas que realiza: numerosas escalas de prejuicio sexual han considerado el reactivo como un indicador de discriminación y estigmatización social que, además, incorpora un fraseo de indagación de un objeto con mayor concreción que otros de los reactivos utilizados.

\section{Tabla 4}

Indicadores estadisticos de la consistencia interna de la EANT

\begin{tabular}{lcc}
\hline EANT & $\begin{array}{c}\text { Correlación } \\
\text { item-total } \\
\text { corregida }\end{array}$ & $\begin{array}{c}\alpha \text { si se } \\
\text { elimina el } \\
\text { elemento }\end{array}$ \\
\hline Está bien que las personas trans puedan adoptar niños (invertido) & .656 & .847 \\
Las personas trans no deberían poder enseñar en las escuelas & .381 & .872 \\
El sexo con una persona trans no es natural & .577 & .854 \\
Las personas travestis son una amenaza para la familia y la sociedad & .544 & .857 \\
Las personas trans tienden a ser sexualmente promiscuas & .709 & .842 \\
Seria chocante ver a una persona trans dando un beso & .712 & .841 \\
Me molestaría que un hijo mío sea travesti & .645 & .848 \\
Las personas trans son más propensas que el resto de la sociedad & .585 & .854 \\
a contraer una enfermedad sexual & & .591 \\
Los travestis son homosexuales disfrazados de mujer & .853 \\
\hline
\end{tabular}

Nota: EANT = Escala de Actitudes Negativas hacia Personas Trans

Asimismo, se realizó un análisis de comparación de medias según la prueba $t$ para muestras independientes, con el fin de analizar las diferencias en las respuestas para cada ítem y el puntaje agregado de la escala entre personas que se identificaron como heterosexuales respecto de quienes no se identificaron como tales. Tratándose de una escala que indaga el prejuicio sexual hacia personas trans, donde el exogrupo es identificado con las personas heterosexuales, se consideró que realizar este análisis resultaría pertinente como mecanismo para validar externamente la escala. Las diferencias resultaron ser significativas estadísticamente, en 
tanto que las personas que se identificaron como heterosexuales mostraron una media más alta que quienes se identificaron como lesbianas, gays, bisexuales, trans (LGBT) u otra categoría, tanto en los ítems de la escala por separado como en el caso del puntaje agregado de la misma (Ver Tabla 5). Solo el ítem Me molestaría que un hijo mío sea travesti no arrojó una diferencia de medias significativa estadísticamente, aunque las personas LGBT y otros/as tendieron a mostrarse más en desacuerdo con dicha afirmación que las personas heterosexuales. Estos datos sugieren que los ítems resultan pertinentes para instrumentalizar una medición de prejuicio sexual hacia personas trans.

A partir del mismo tipo de análisis es posible advertir que las personas que han oído hablar de la noción trans presentan una media menor de actitudes desfavorables hacia personas trans que las personas que no conocían previamente la noción $(F=7.313 ; p \leq .05)$. Sin embargo, no se advirtió una diferencia de medias estadísticamente significativa entre quienes manifestaron conocer respecto a quienes no conocen a una persona trans, lo cual sugeriría que el contacto social no presentaría el mismo efecto liberalizador de las actitudes hacia personas trans que en otras mediciones de prejuicio analizadas por diversos antecedentes.

Finalmente se realizaron correlaciones bivariadas entre el puntaje agregado de la EANT y variables sociodemográficas, de religiosidad y de la escala de actitudes hacia gays y lesbianas (ATLG). Como puede advertirse en la Tabla 6, la EANT se relaciona positivamente y de forma débil con la edad y la frecuencia de asistencia al culto, de forma negativa y débil con el nivel educativo, el NSE y la dimensión Dominancia Grupal de la Orientación hacia la Dominancia Social, mientras que lo hace de forma positiva y moderada con la intensidad del sentimiento religioso y el autoritarismo de Ala de Derecha. ATLG presenta una correlación fuerte y significativa con la EANT. El sentido de las relaciones coincide con lo relevado por nuestros antecedentes, y la fuerza de las correlaciones es mayor en comparación a la muestra 1 que resultaba más homogénea en términos de su composición sociodemográfica. 


\section{Tabla 5}

Prueba de comparación de medias entre personas heterosexuales y no heterosexuales para la escala de actitudes negativas hacia personas trans en estudio poblacional

\begin{tabular}{|c|c|c|c|}
\hline & & $M(D E)$ & $F$ \\
\hline \multirow{2}{*}{$\begin{array}{l}\text { Está bien que las personas trans puedan } \\
\text { adoptar hijos }(\mathrm{R})\end{array}$} & LGBT y otros & $1.70(1.02)$ & \multirow{2}{*}{$12.08^{* *}$} \\
\hline & Heterosexuales & $3.71(1.55)$ & \\
\hline \multirow{2}{*}{$\begin{array}{l}\text { Las personas trans no deberían poder } \\
\text { enseñar en las escuelas }\end{array}$} & LGBT y otros & $1.52(1.27)$ & \multirow{2}{*}{$13.09^{* *}$} \\
\hline & Heterosexuales & $2.50(1.58)$ & \\
\hline \multirow{2}{*}{$\begin{array}{l}\text { El sexo con una persona trans no es } \\
\text { natural }\end{array}$} & LGBT y & $1.35(.93)$ & \multirow{2}{*}{$30,06^{* *}$} \\
\hline & Heterosexuales & $3.33(1.59)$ & \\
\hline \multirow{2}{*}{$\begin{array}{l}\text { Las personas travestis son una amenaza } \\
\text { para la familia y la sociedad }\end{array}$} & LGBT y otros & $1.00(.00)$ & \multirow{2}{*}{$69,06^{* *}$} \\
\hline & Heterosexuales & $2.09(1.46)$ & \\
\hline \multirow{2}{*}{$\begin{array}{l}\text { Las personas trans tienden a ser sexual- } \\
\text { mente promiscuas }\end{array}$} & LGBT y & 3) & \multirow{2}{*}{$12,05^{* *}$} \\
\hline & Heterosexuales & $3.25(1.54)$ & \\
\hline \multirow{2}{*}{$\begin{array}{l}\text { Seria chocante ver a una persona trans } \\
\text { dando un beso }\end{array}$} & LGBT y otros & $1.17(.49)$ & \multirow{2}{*}{$57,91^{* *}$} \\
\hline & xuales & $1(1.60)$ & \\
\hline \multirow{2}{*}{$\begin{array}{l}\text { Me molestaría que un hijo mío sea tra- } \\
\text { vesti }\end{array}$} & LGBT y otros & $2.09(1.24)$ & \multirow{2}{*}{1.81} \\
\hline & Heterosexuales & $3.65(1.48)$ & \\
\hline \multirow{2}{*}{$\begin{array}{l}\text { Las personas trans son más propensas } \\
\text { que el resto de la sociedad a contraer una } \\
\text { enfermedad sexual }\end{array}$} & LGBT y o & 1.6 & \multirow[b]{2}{*}{$15.22^{* *}$} \\
\hline & Heterosexuales & $3.19(1.62)$ & \\
\hline \multirow{2}{*}{$\begin{array}{l}\text { Los travestis son homosexuales disfraza- } \\
\text { dos de mujer }\end{array}$} & LGBT y otros & $1.30(1.02)$ & \multirow{2}{*}{$27.38^{* *}$} \\
\hline & Heterosexuales & $3.02(1.65)$ & \\
\hline \multirow[t]{2}{*}{ EANT (puntaje agregado) } & LGBT y otros & $13.30(4.30)$ & \multirow{2}{*}{$27.35^{* *}$} \\
\hline & Heterosexuales & $28.03(9.82)$ & \\
\hline
\end{tabular}

Nota: ${ }^{*} p \leq .05 ;{ }^{* *} p \leq .01$

$n$ (heterosexuales $)=387 ; n$ (LGBT y otros $)=23$ 


\section{Tabla 6}

Correlaciones entre escala de actitudes negativas hacia personas trans $y$ variables independientes

\begin{tabular}{|c|c|c|c|c|c|c|c|c|c|}
\hline & EANT & Edad & $\begin{array}{l}\text { Nivel } \\
\text { Educ. }\end{array}$ & NSE & $\begin{array}{l}\text { Frec. } \\
\text { Culto }\end{array}$ & $\begin{array}{l}\text { Int. } \\
\text { Rel. }\end{array}$ & $\begin{array}{c}\text { SDO } \\
\text { DG }\end{array}$ & RWA & ATLG \\
\hline EANT & 1 & $.304^{* \prime}$ & $-.461^{*^{*}}$ & $-.405^{* *}$ & $.305^{* *}$ & $.581^{* *}$ & $.211^{* *}$ & $.502^{* *}$ & $.779^{* *}$ \\
\hline Edad & & 1 & -.042 & .035 & $.155^{* *}$ & $.322^{* *}$ & .015 & $.161^{* *}$ & $.311^{* *}$ \\
\hline Nivel Educ & & & 1 & $.758^{* *}$ & $-.218^{* *}$ & $-.406^{* *}$ & .028 & $-.162^{* *}$ & $-.431^{* *}$ \\
\hline NSE & & & & 1 & $-.212^{* *}$ & $-.365^{* *}$ & .051 & $-.479^{* *}$ & $-.385^{* *}$ \\
\hline Frec. culto & & & & & 1 & $.591^{* *}$ & .061 & $.356^{* *}$ & $.295^{* *}$ \\
\hline Int Rel & & & & & & 1 & $.185^{* *}$ & $.499^{* *}$ & $.570^{* *}$ \\
\hline SDO DG & & & & & & & 1 & $.317^{* *}$ & \\
\hline RWA & & & & & & & & 1 & \\
\hline ATLG & & & & & & & & & 1 \\
\hline
\end{tabular}

Nota: ${ }^{*} p \leq .05 ;{ }^{* *} p \leq .01$

Nivel Educ $=$ Nivel Educativo del Encuestado; NSE= Nivel socioeconómico; Frec. Culto = Frecuencia de Asistencia al Culto; Int. Rel =Intensidad Religiosa; SDO DG: Dominancia grupal de la Orientación hacia la Dominancia Social; RWA = Autoritarismo de Ala de Derecha ATLG = Actitudes hacia lesbianas y gays.

A su vez, y como puede apreciarse en la Figura 2, se compararon los niveles de prejuicio encontrados en el estudio instrumental y en el poblacional, registrándose que en el estudio instrumental el nivel de prejuicio encontrado fue menor que en el poblacional, posiblemente debido a la homogeneidad de la muestra. Los niveles de prejuicio fueron categorizados a partir de las desviaciones estándar de ambas escalas. Las diferencias descriptivas en torno a la presencia y distribución del prejuicio hacia personas trans en ambos estudios, sugieren la necesidad de no descansar solo en estudios con poblaciones estudiantiles (con mayor nivel socioeconómico y educativo que la media poblacional) a la hora de estudiar los prejuicios sexuales y de género. 


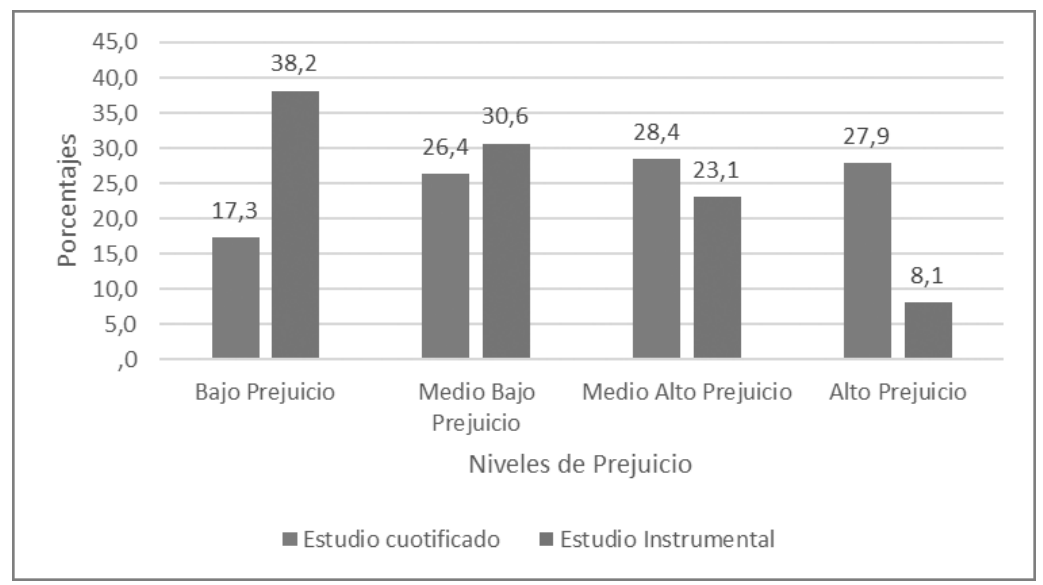

Figura 2. Niveles de prejuicio de ciudadanos cordobeses en estudio 1 y 2

\section{Discusión}

Los resultados de los análisis realizados en el presente estudio instrumental indican que es posible considerar validada interna y externamente la escala de actitudes negativas hacia personas trans construida. Si bien las relaciones con variables sociodemográficas son débiles, las correlaciones adquieren mayor intensidad al trabajarse con una muestra de población ampliada (estudio 2), que en la muestra más homogénea compuesta en su mayoría por estudiantes universitarios/as y personas jóvenes o vinculadas al sector académico. La EANT mostró una estructura unidimensional a partir de análisis factoriales consistente, tanto exploratorios como confirmatorios. Las correlaciones positivas y fuertes con constructos similares (como ATLG), y negativas y moderadas con variables de religiosidad, van en consonancia con antecedentes relevados en otros contextos. De esta forma, la validación externa de la EANT sugiere que las personas con mayor intensidad del sentimiento religioso y con mayor frecuencia de asistencia al culto presentan mayores niveles de actitudes desfavorables hacia personas trans, mientras la educación y el NSE impactan de forma inversa, reduciendo el nivel de prejuicio evidenciado. 
El estudio científico del prejuicio no se produjo hasta que el mismo fue reconocido como una problemática social y desde entonces se han estudiado paulatinamente las actitudes hacia distintas minorías que los estudiosos han considerado objeto de problematización social. El estudio del prejuicio hacia las personas travestis, transexuales y transgénero constituye en la actualidad un tema que cobra auge debido a las diferentes luchas que se han llevado a cabo desde distintos movimientos sociales, y a la frecuente invisibilización de sus demandas y problemáticas de discriminación y exclusión. Sin embargo, las producciones teóricas que puedan describir y explicar las actitudes negativas hacia estas personas son aun escasas, fragmentadas y asistemáticas.

Las diferencias de medias identificadas en los puntajes de la EANT para personas heterosexuales respecto de no heterosexuales, así como para personas que conocen u han oído hablar de la noción "trans" respecto a las que no, sugieren que se trata de una valoración válida de prejuicio intergrupal. La falta de evidencias significativas respecto a las diferencias de medias entre personas que conocen personalmente a personas trans habilita a cuestionar, por un lado, el tipo de mediciones implementadas para indagar el contacto social y, por otro, los efectos del contacto y la proximidad social en las actitudes hacia poblaciones vulneradas sistemáticamente, a partir de creencias sobre sexualidad y género férreamente asentadas en nuestras sociedades. Se trata, no obstante, de una cuestión que requiere mayores profundizaciones en futuros trabajos. Los resultados también sugieren la pertinencia de considerar la hipótesis de transferencia seńalada por Norton y Herek (2012), a la hora de pensar en las vinculaciones entre el prejuicio hacia personas gays y lesbianas, y hacia personas trans entre sí, aunque consideramos que teóricamente es necesario evitar la simplificación de asociar el prejuicio hacia estas personas gays y lesbianas, con el prejuicio hacia personas trans.

Consideramos que la escala de actitudes negativas hacia personas trans diseñada y validada en la investigación, puede constituir una contribución relevante por diversas razones. Al momento de su elaboración no se habían registrado trabajos que contaran con instrumentos 
adecuados destinados a conocer las actitudes hacia estas personas en población ampliada. Los trabajos relevados recurren a la evaluación de constructos como la transfobia o emplean termómetros de sentimientos como instrumentos para conocer las actitudes hacia las personas trans, mientras que en nuestra propuesta se enfatizan las actitudes desfavorables presentes en la población hacia las personas trans. Es por esto que la construcción de una escala a nivel local podría constituir un valioso aporte al estudio del prejuicio, y puede redundar en contribuciones significativas a futuro que analicen los efectos socioculturales de la promulgación de la Ley de Identidad de Género hace dos años atrás. Dado el interés de avanzar en la validez y replicabilidad de la escala, se requeriría conocer su potencial aplicación a otros contextos diferentes al argentino.

A su vez, a pesar de tratarse de reactivos que recogen actitudes manifiestas, los niveles de actitudes negativas hacia personas en la población en general tienden a ser altos, lo cual plantea la necesidad de continuar trabajando en las transformaciones de las actitudes sociales de aceptación de las diversidad sexo-genéricas y en la disminución del prejuicio.

Finalmente, cabe destacar que existe una discusión intensa en la política y la academia abocada al estudio de las luchas sociosexuales respecto a los efectos deseados y no deseados de las legislaciones y políticas públicas en clave de derechos sexuales y reproductivos (Miller, 2003). Aún se requieren mayores evidencias empíricas para sostener que el reconocimiento legal de derechos impacta favorablemente en el reconocimiento social. Una aplicación periódica de la EANT en población ampliada podría brindar evidencias a futuro en esta dirección. Como ventaja, el instrumento propuesto incluye solo 9 ítems, una extensión adecuada para trabajar con muestreos poblacionales, y que, en conjunto con otros instrumentos, podría facilitar su indagación en encuestas científicas y sondeos de opinión pública, a la vez que brindaría una mayor disposición de información pertinente y mayor complejidad en los análisis consecuentes. 


\section{Referencias}

Boletín Oficial, Congreso de la Nación. (2012, Mayo) Identidad de Género. Ley 26.743. Recuperado de http://www.boletinoficial. gov.ar/Inicio/Index.castle

Cabral, M. (2011). La paradoja transgénero. En C. Cáceres, M. E. Mogollón, G. Pérez-Luna \& F. Olivos (Eds.), Sexualidad, ciudadania y Derechos Humanos en América Latina (pp. 97-104). Lima: Instituto de Estudios en Salud, Sexualidad y Desarrollo Humano.

Castillo, M., Rodríguez, V., Torres, R., Pérez, A. \& Martel, É. (2003). La medida de la homofobia manifesta y sutil. Psicothema, 15, 197-204.

Claman, E. E. (2007). An examination of the predictors of attitudes toward transgender individuals. Tesis Doctoral, The Ohio State University. Recuperado de https://etd.ohiolink.edu/ap/10?0:: NO:10:P10_ACCESSION_NUM:osu1218227559

Comisión de Enlace Institucional, AAM, SAIMO \& CEIM. (2006). Nivel Socio Económico 2006. Recuperado de http://www.saimo. org.ar/socios/Socios/NSE2006-23nov2006-Informe_final.pdf

Elorza Pérez-Tejeda, H. (2008). Estadística para las ciencias sociales, del comportamiento y de la salud. México D. F.: Cencage Learning.

Ferrando, P. J. \& Anguiano-Carrasco, C. (2010). El análisis factorial como técnica de investigación en psicología. Papeles del psicólogo, 31(1), 18-33.

George, D. \& Mallery, M. (2011). SPSS for Windows step by step: A simple guide and reference 18.0 update (11th Edition). Boston, MA: Allyn \& Bacon.

Gerhardstein, K. R. \& Anderson, V. N. (2010). There's more than meets the eye: Facial appearance and evaluations of transsexual people. Sex roles, 62(5-6), 361-373.

Grasmick, H. G., Cochran, J. K., Bursik, R. J. \& Kimpel, M. L. (1993). Religion, punitive justice, and support for the death penalty. Justice Quarterly, 10(2), 289-314. 
Herek, G. (1988). Heterosexuals' Attitudes toward Lesbians and Gay Men: Correlates and Gender Differences. The Journal of Sex Research, 25, 451-477.

Herek, G. (1994). Beyond Homophobia: A social psychological perspective in attitudes toward lesbians and gay men. Journal of Homosexuality, 10, 2-17.

Herek, G. (2000). Sexual prejudice and gender: Do heterosexuals' attitudes toward lesbians and gay men differ? Journal of Social Issues, 56, 251-266.

Hill, D. \& Willoughby, B. (2005). The development and validation of the genderism and transphobia scale. Sex Roles, 53, 531-544.

Hill, D. B. (2002). Genderism, transphobia, and gender bashing: A framework for interpreting anti-transgender violence. En B. Wallace \& R. Carter (Eds.), Understanding and dealing with violence: A multicultural approach (pp. 113-136). Los Ángeles: Sage Publications.

Imhoff, D. \& Brussino, S. (2012). Análisis psicométrico de la dimensión autoritarismo general de la escala RWA en CórdobalArgentina. Manuscrito inédito. Recuperado de http://psychepolitica.files. wordpress.com/2012/05/2-imhoff-y-brussino.pdf

Instituto Nacional Argentino contra la Discriminación, el Racismo y la Xenofobia (2012). Buenas prácticas en la comunicación pública. Recuperado de http://inadi.gob.ar/comunicacion/informes/

Instituto Nacional de Estadísticas y Censos (2011). Censo Nacional de Población, Hogares y Viviendas. Recuperado de http://www. indec.mecon.ar

Iosa, T., Rabbia, H., Sgró Ruata, M. C., Morán Faúndes, J. M. \& Vaggione, J. M. (2012) Politica, sexualidades y derechos. Primera encuesta marcha del orgullo y la diversidad. Río de Janeiro: CLAM y UNC. Recuperado de http://www.clam.org.br/ uploads/arquivo/Pol\%C3\%ADtica, $\% 20$ sexualidades $\% 20 y \% 20$ derechos\%20-\%20Marcha\%20C\%C3\%B3rdoba.pdf

Jaume, L. C., Etchezahar, E. D., Cervone, N. C. \& Biglieri, J. (2011). Adaptación y validación de la escala Orientación a la 
dominancia Social (SDO) al contexto argentino mediante AFC. Anuario de investigaciones, 18, 237-242. Recuperado de http:// www.scielo.org.ar/scielo.php?script=sci_arttext $\&$ pid $=S 1851$ $16862011000100025 \& \operatorname{lng}=\mathrm{es} \& \mathrm{nrm}=\mathrm{iso}$

Kooy, R. E. (2010). Knowledge and attitudes toward trans persons (Tesis doctoral, Humboldt State University, California, Estados Unidos). Recuperado de http://humboldt-dspace.calstate. edu/bitstream/handle/2148/693/Kooy\%20Thesis\%202010. pdf?sequence $=5$

Landén, M. \& Innala, S. (2000). Attitudes toward transsexualism in a Swedish national survey. Archives of Sexual Behavior, 29(4), 375-388.

Larsen, K. S., Reed, M. \& Hoffman, S. (1980). Attitudes of heterosexuals toward homosexuality: A likert-type scale and construct validity. Journal of Sex Research, 16(3), 245-257.

Lista, C. (1995). ¿Existe consenso hacia el aborto inducido?: tendencias de la población de la ciudad de Córdoba. Córdoba: UNC.

Lohr, S. (2000) Muestreo: diseño y análisis. México: Thompson.

Luijk, G. (2010). ¿Qué es un histograma? Recuperado de http://www. guillermoluijk.com/article/histogram/

Moral de la Rubia, J. (2010). Religión, significados y actitudes hacia la sexualidad: Un enfoque psicosocial. Revista Colombiana de Psicología, 19(1), 45-59.

Miller, A. (2003). La demanda por los derechos sexuales. Ponencia del III Seminario Regional, Derechos Sexuales, Derechos reproductivos, Derechos Humanos, Comité de América Latina y el Caribe para la defensa de los Derechos de la Mujer. Recuperado de http://www.rebelion.org/hemeroteca/mujer/030616miller.htm

Mola, D. J., Saavedra, B. A., Reyna, C. \& Belaus, A. (2013). Valoración psicométrica de la psychological entitlement scale desde la teoría clásica de los tests y la teoría de respuesta al ítem. Pensamiento Psicológico, 11(2), 19-38. 
Morales Vallejo, P. (2011). Guía para construir cuestionarios y escalas de actitudes. Recuperado de http://blog.uca.edu.ni/kurbina/ files/2011/06/guiaparaconstruirescalasdeactitudes.pdf

Morales Vallejo, P. (2013). El análisis factorial en la construcción e interpretación de tests, escalas y cuestionarios. Recuperado de http://web. upcomillas.es/personal/peter/investigacion/AnalisisFactorial.pdf Nagoshi, J., Adams, K., Terrell, H., Hill, E., Brzuzy, S. \& Nagoshi, C. (2008). Gender Differences in Correlates of Homophobia and Transphobia. Sex Roles, 59, 521-531.

Norton, A. T. \& Herek, G. M. (2012). Heterosexuals' attitudes toward transgender people: Findings from a national probability sample of US adults. Sex roles, 68(11-12), 738-753.

Organización de Transexuales por la Dignidad de la Diversidad [OTD] \& International Gay and Lesbian Human Rights Commission [IGLHRC] (2012). Violaciones de derechos humanos de las personas lesbianas, bisexuales y transexuales [LBT]: Un informe sombra. Presentado a la Sesión $n^{\circ} 52$ de la Convención Sobre la Eliminación de Todas Las Formas de Discriminación Contra la Mujer [CEDAW]. Septiembre 2012, Santiago de Chile. Recuperado de https://iglhrc.org/sites/default/files/583-1.pdf

Pérez, E., Medrano, L. A. \& Sánchez Rosas, J. (2013). El path analysis: conceptos básicos y ejemplos de aplicación. Revista Argentina de Ciencias del Comportamiento, 5(1), 52-66.

Pratto, F., Sidanius, J., Stallworth, L. \& Malle, B. F. (1994). Social dominance orientation: A personality variable predicting social and political attitudes Journal of Personality and Social Psychology, 67(4), 741-763.

Riggs, D. W., Webber K. \& Fell, G. (2012). Australian undergraduate psychology students' attitudes towards trans people. Gay \& Lesbian Issues and Psychology Review, 8(1), 52-62.

Rodríguez-Castro, Y., Lameiras-Fernández, M., Carrera-Fernández, V. \& Vallejo-Medina, P. (2013). Validación de la escala de homofobia moderna en una muestra de adolescentes. Anales de psicología, 29(2), 523-533. 
Rottenbacher de Rojas, J. M. (2012). Conservadurismo político, homofobia y prejuicio hacia grupos transgénero en una muestra de estudiantes y egresados universitarios de Lima. Pensamiento Psicológico, 10(1).

Seoane, J. \& Garzón, A. (1992). Creencias sociales contemporáneas, autoritarismo y humanismo. Psicología Política, 5, 27-52.

Tabachnick, B. G. \& Fidell, L. S. (2001). Using multivariate statistics. Northridge: Pearson.

Turizo, J. M. \& Iglesia, M. A. (2011). Conquistas legales no traducen ipso facto conquistas sociales. Especial referencia a los reconocimientos jurídicos de la comunidad LGBT. Justicia Juris, 7(1), 79-92.

Willoughby, B. L., Hill, D. B., Gonzalez, C. A., Lacorazza, A., Macapagal, R. A., Barton, M. E. \& Doty, N. D. (2010). Who hates gender outlaws? A multisite and multinational evaluation of the Genderism and Transphobia Scale. International Journal of Transgenderism, 12(4), 254-271.

Winter, S., Chalungsooth, P., Teh, Y. K., Rojanalert, N., Maneerat, K., Wong, Y. W. ... \& Macapagal, R. A. (2009). Transpeople, transprejudice and pathologization: A seven-country factor analytic study. International Journal of Sexual Health, 21(2), 96-118.

Winter, S., Webster, B. \& Cheung, P. K. E. (2008). Measuring Hong Kong undergraduate students' attitudes towards transpeople. Sex Roles, 59(9-10), 670-683.

Wright, L. W., Adams, H. E. \& Bernat, J. (1999). Development and validation of the Homophobia Scale. Journal of Psychopathology and Behavioral Assessment, 21, 337-347.

Recibido: 22 de septiembre, 2014 Aceptado: 27 de octubre, 2014 